\title{
Shaping a healthy future: youth as a smart investment
}

\section{A glimpse of youthful needs in sexual and reproductive health}

\author{
Janaki Vidanapathirana \\ President, College of Community Physicians of Sri Lanka, 2018/19 \\ Correspondence: kavigaya@yahoo.com (iD https://orcid.org/0000-0002-0444-8596 \\ DOI: https://10.4038/jccpsl.v25i3.8225
}

Received on: 28 June 2019

Accepted on: 30 June 2019

“Ms Ruwini, a 16-year old petite girl hailing from a single parent family in an urban setup was doing well in her studies in grade 11 while her mother worked in a government office as a labourer. One unfortunate day, she was raped by a mason working next door and was threatened not to reveal the incident. Four months later, she realized she was pregnant but did not reveal it to anyone. When it was difficult to hide her pregnancy, she decided to commit suicide at 35 weeks. She wrote a letter to her mother explaining everything and also telling her how to cope up with the sorrow after her loss. The mother found the letter before Ruwini could commit the act and was wise enough to immediately seek health services. A team of healthcare professionals attended to Ruwini and cared for her for the rest of the pregnancy in a highly confidential manner. The baby was given for adoption. When the school authorities refused to take her back doubting about a pregnancy, the health team issued a note mentioning that she has undergone a surgery due to health reasons. She commenced schooling after a lapse of 2 months. Few months later, she sat for the O/Level examination and obtained 9 A passes. Last year, she was successful in obtaining three A passes in her A/Level examination. She is now awaiting university entrance”.

"In 2010, a well-known female HIV activist came to meet a consultant at the National STD/AIDS Control
Programme (NSACP) accompanied by a handsome yet depressed young boy. She informed that this boy was a member in their organization and requested to find a job for him who also had passed his A/Level examination. Since the consultant did not have the capacity to find jobs in the government sector, there was no way to help this boy. However, this HIV activist did not give up and kept requesting repeatedly. She also mentioned that this boy was frustrated and was having suicidal ideas at times. After repeated requests, the consultant had a talk with the UNFPA, and they agreed to give him a job as a youth coordinator in the unit. The then Director, NSACP also gave his permission, and this boy commenced work. Soon it was evident that he was clever and acquired new skills day by day in planning, organization, partnership and negotiation. He worked with all the sectors and supported in research work carried out by the consultant. He also presented a research paper for the 14th International AIDS Conference in USA in 2012. He got opportunities of study tours to Malaysia and Thailand with the support of UNFPA, UNAIDS and AIDS Foundation. Later, he initiated his own work as a youth advocate. Now he leads a very productive life with a stable monthly salary, and is a valuable asset to other youth. He is so grateful to this HIV activist and the team at NSACP and UNFPA for his achievements". 
The two real-life stories given are evidence on how investment of people pave way for youth to find new lives. Sexual and reproductive health (SRH) is an essential element of human health and wellbeing of a person for sustainable development.

\section{Young people and SRH}

If we consider young people, although they live in diverse socio-cultural and economic contexts, they share common challenges related to $\mathrm{SRH}$, despite, many programmes being in place to promote SRH. They face the extra vulnerabilities with regard to SRH due to being young. Young people are generally thought to be at the healthiest point of their life. Yet, unhealthy lifestyles in youth can lead to many health issues in later life.

The World Health Organization (WHO) defines 'adolescents' as persons aged 10-19 years. The term 'youth' covers the population group aged 15-24 years. Collectively, adolescents and youth are known as 'young people', ranging from 10-24 years. In the text to follow, those aged 10-24 years are considered as 'young'.

Young people experience rapid and profound changes in physical and psychosocial aspects including development of individual identities. In many laws, young people are recognized as adults at the age of 18 years. However, they are more prone to risky behaviour until they are 25 years old, since the per-frontal cortex which helps to think before acting is developed only in the mid-twenties.

Many adults see young people as pieces of a puzzle and always advise them rather than facilitate. Parents and teachers see them as non-functional without their advice and tend to always advise them. Health workers see them only as patients. They further try to impose their own cultural or religious values on sexuality on the youth. Law enforcement officers see them as possible juvenile delinquents while businessmen see them as consumers without money. However, young people are fun-loving, adaptable, curious, trustworthy, creative, resourceful and quite different from adults. They are technologically strong, conscious about the environment and work hard for a cause. They prefer independence and their trend is towards social networking. However, sometimes adults may see them as being disrespectful. Not realizing the individual variation of identities and needs of youth, it leads to a mismatch in interactions between youth and adults. Mismatch affects the holistic development of youth One size does not fit all. When the barriers to information are considered, these mismatches lead to barriers for optimum SRH among young people. Service providers have negative attitudes on sexuality and an understanding that young people are not sexually active. This is further aggravated by some legal barriers that make them vulnerable, leading to situations such as poor access to services, especially related to contraceptives or sexually transmitted infections (STI).

\section{Investing in young people}

Latest evidence shows that investments in young people's health give rise to a ten-fold economic benefit and generate high economic returns. By analysing the current evidence, it can identify where the investments could be done effectively. The rationale for investment can be categorized under four broad areas, namely demographic rationale, public health rationale, economic rationale and human rights rationale.

\section{- Demographic rationale}

Demographic rationale is based on the fact that young people make up $24 \%$ (i.e. 1.8 billion) of the 7.3 billion global population. This number is set to rise to 2 billion by 2032. Today's cohort of young people is the largest in history, and $89 \%$ of them live in developing countries. If we focus on Sri Lanka, it is home to $24 \%$ of young people out of the 21.4 million total population. According to the latest population censes analysis, the window of opportunity to invest in youth exists from 1992 to 2037. If Sri Lanka invests wisely in education, health and economic opportunities for youth using this window of opportunity before 2037, achieving sustainable development will not be a challenge.

\section{- Public health rationale}

Every year, about 1.4 million adolescents die globally and many of these deaths are preventable. The SRH problems account for $18 \%$ of the total global burden of diseases. Adolescent birth rates range between the highest value of 120 and the lowest of 30 per 15-19 aged women in the Asia Pacific Region. Teenage pregnancies are considered a serious health and social problem for both the mother and baby. 
Sri Lanka shows the lowest total fertility rate in the region, which was 2.2 in 2016. A significant number of teenage pregnancies occur each year, which is around 180,00-240,00 during the last five years in Sri Lanka. The percentage of teenage pregnancies has been relatively static during the past few years ranging from $4.6 \%$ to $5.3 \%$. When the fertility rate of young women aged 15-19 years who gave birth or are pregnant with their first child in Sri Lanka is considered, this is also a static figure, with an adolescent pregnancy rate of $31 \%$ in 1975 and $32 \%$ in 2016 . This indicates that there is no clear difference during the last four decades, highlighting that urgent investment is necessary to reduce the teenage pregnancies and adolescent fertility.

Investments in provision of contraceptives yield social and economic returns and reduced maternal and infant mortality. Demographic and Health Survey (DHS) 2016 revealed that the contraceptive prevalence rate among women aged 15-49 years was 65\% in Sri Lanka and was the highest in the region. However, it was only $43 \%$ among the currently married 15-19year old group, which was equal to the lowest value in the region. This indicates that the country needs to pay more attention to improve the situation of young married women in Sri Lanka.

\section{Young people and HIV}

Sri Lanka continues to have a low prevalence of HIV and it accounts to $0.01 \%$ among adults. The numbers of new estimated HIV infections show a rapid decline and had stabilized in 2016. The reported number of new HIV infections is increasing each year, and this can be mainly attributed to accelerated HIV testing. In $2017,44 \%$ of the new cases occurred due to heterosexual transmission of the virus while $42 \%$ of the cases were due to male-to male sexual transmission. New HIV infections among 15-24-year age group had been on average $10 \%$ of the total new infections for the past eight years. This also highlights that urgent attention needs to be paid to young people to prevent HIV. This is very important to achieve the Sri Lankan target on ending AIDS by 2025; that is five years before the global target of 2030 .

\section{Young people and sexual abuse}

Sexual abuse gives short- and long-term complications related to physical, mental and social wellbeing. Globally, 15 million adolescent girls aged
15-19 years have experienced forced sex in their lifetime. The DHS 2016 revealed that 3\% of evermarried women aged 15-24 years reported having their first sexual intercourse before the age of 15 years. Further, out of all the child abuse cases received by the National Child Protection Authority during the year $2017,12 \%$ had been child sexual abuse cases.

\section{Inter-generational implications of poor SRH}

Adverse SRH can lead to ill effects from generation to generation and the deterioration of the health of young people as they go down the social ladder. It is proven that poverty, low education and lack of life skills lead to decreased autonomy for life events. This leads to early marriage, sexual exploitation, lack of power, violence and less access to health services. These factors lead to increased maternal and infant morbidity and mortality, and increased HIV/ STIs.

\section{- Economic rationale}

Investing on young people brings a triple dividend effect. This includes reducing death and disability, promoting health and productivity across the life-course and providing the best possible start to life. Failing to invest in young people triggers substantial economic, social, and political costs resulting from negative outcomes such as risky sexual behaviour, substance abuse, crime, violence and poor labour market entry. The overall damage to the society amounts to several percent of the gross domestic product per year losses to society that reach into billions of dollars.

Famous Economist James Heckman has shown the rate of return to human capital investment at different ages. He has pointed out that the highest rate of economic returns comes from the earliest investments in human life with a greater return of investment and reduction of social spending. The second and last chance of opportunity for investment lies is in the lives of young people.

The maximum intensity of brain development occurs during the period from conception to first three years of life. Further, the ability of the brain to change in response to experiences is very high during the first four years of life, after which it gradually slows down. However, many countries including Sri Lanka are spending large amounts of public expenditure during 
later life. This should be an eye-opener on the society investing too much money on later stages of life, and this leads to a delay in getting a return of investment. In this context, 10-24 years is the last opportunity to get maximum benefits. Globally, the average national percentage of total government expenditure devoted to health was $11.7 \%$ in 2014 . Compared to this, Sri Lanka allocated $4.47 \%$ for 'health' and $2.58 \%$ for 'education' out of the total budget of 3982 billion in 2018. The allocation for 'early childhood education and development' was even lower than that.

\section{- Human rights rationale}

Rights are legal, social or ethical principles of freedom or entitlement. In other words, "A right is not something that somebody gives you; it is something that nobody can take away". The SRH rights embrace human rights. According to the WHO, sexual rights can be explained as the right to have pleasurable and safe sexual relationships free of coercion, discrimination and violence, while the right to decide freely on the number, spacing and timing of children and to have information can be explained as reproductive rights.

Sexual rights that are recognized in the national laws and numerous conventions signed by Sri Lanka, reaffirm human rights. The Constitution of the Democratic Socialist Republic of Sri Lanka 1978 recognizes equal fundamental human rights for all. Although health has not been recognized as a right in the constitution, Articles 11, 12, $14 \& 27$ of the constitution ensure wellbeing of physical, mental and social aspects including SRH rights. There are no special laws for youth in the constitution, but common laws cover the protection and wellbeing of youth.

Many international conventions, policies, strategies and programmes in Sri Lanka oversee and ensure a conducive environment for SRH. This provides information and services without discrimination of young people to make informed decisions about SRH. National Youth Policy and National Youth Health Policy of Sri Lanka have further strengthened these SRH rights.

\section{Laws that regulate sexuality in Sri Lanka}

Laws need to balance autonomy and protection. The country has specified the minimum age of sexual consent as 16 years by considering the evolution capacity of young people. Minimum age of marriage in Sri Lanka is 18 years, which does not allow child marriages except among Muslims. Laws do not prevent access to SRH services by young people. However, the society has an impression that there is a barrier. Sri Lanka has laws against rape, and sexual and domestic violence. However, no legal provisions are available against marital rape. This can affect the lives of young married girls who do not have autonomic capacity over their bodies.

A recent report submitted to the Minister of Justice by the Salim Musruf Committee indicated that many Muslim child marriages below 18 years are reported in the Eastern and Western Provinces and has recomended for changing the existing Muslim Marriage law.

The Ministry of Health has recognized barriers when providing SRH services for adolescents, due to the misunderstandings of law enforcement officers. After obtaining clearance from the Attorney General, the Ministry of Health has issued circulars with directions to deliver SRH services including contraceptive and HIV testing for those below the age of 18 years, even without the permission of their legal guardians, considering the best interest of the adolescent. Further, according to these circular, medical officers do not have a legal duty to report teenage pregnancies in those less than 16 years. Despite the training, still certain issues arise from time to time due to the negative attitudes of some law enforcement officers.

\section{Laws in Sri Lanka and their impact}

Section 365(a) of the Sri Lankan Penal Code mentions that 'gross indecency' between two persons is a criminal offence, and punishable with imprisonment. However, law has not defined what gross indecency is. This is considered the same as sexual behaviour by the law authorities. It leads to barriers for SRH services of young men who have sex with men (MSM). The stigma associated with same sexual behaviour creates significant barriers for accessing services and use of condoms especially among young people.

There is no specific legal offence in commercial sex work in private. However, legal documents related to many facets of sex work, namely Vagrancy 
Ordinance, Brothels Ordinance and House of Detention Ordinance make young sex workers reluctant to access SRH services and to carry condoms to be used when in need. It should be noted that condoms are categorized as an essential medical item in the essential drug list of the Ministry of Health Sri Lanka.

Legal barriers and social stigma lead to higher risk of acquiring HIV among sex workers and MSMs. The number of court cases filed under the Vagrancy Ordinance and Brothel House Ordinance and the number of court cases against sexual activities among MSMs have come down with the continuous training programmes for the Police sector by the NSACP. In 2017, the Police Department has issued an internal circular mentioning that condoms cannot be produced to courts as proof for sex work. However, still negative attitudes give rise to problems that affect the outreach HIV testing activities conducted by non-governmental organizations under the supervision of the Ministry of Health.

It is high time to repeal 365(a) and the Vagrancy Ordinance. It is identified in the National Strategic Plan of HIV/STI 2018-2022 to protect human rights especially of young key populations. It is also noteworthy that the Indian Supreme Court decriminalized homosexuality recently.

\section{Transgenderism and access to health services}

Transgenderism is not a disease and has been removed from the ICD-version 11 as well. Young transgender people face stigma and discrimination due to poor understanding of the society and they face many SRH problems. Transgender populations especially young people are at 49 times higher risk of acquiring HIV compared to the general population. Although Sri Lankan law does not specifically criminalize transgender people, no laws ensure that their rights are protected.

The SRH services are provided by island-wide STD clinics, and separate targeted HIV prevention interventions have been started from 2018 for transgender people. Other transgender health services are provided by a very few government hospitals with minimum surgical facilities. Issuing of Gender Recognition Certificate to the Registrar General has been confirmed by the Ministry of Health (General Circular Number: 01-34/2016) to facilitate the obtaining of birth certificate by changing the biological sex. However, it is unders- tood that transgender health services need to be improved in Sri Lanka.

\section{Abortions and young people}

Globally, three million girls aged 15-19 years undergo unsafe abortions every year, while 250,000 women undergo illegal abortions annually in Sri Lanka. The International Federations of Gynaecologists and Obstetricians recommended abortions, by balancing the medical reasons and the women's rights to protect the autonomy of their bodies. This recommendation is evidenced in the guidance given by the WHO.

Although Sri Lankan laws allow the right to the highest attainable standard of wellbeing, abortion is only permitted to save the life of a woman. Social barriers to accessing contraceptives for unmarried young people leave a disproportionate impact on young women. The criminalization of abortion may serve to solidify stigma associated with sexual activity among young people.

Worldwide evidence shows that legal restrictions on abortion do not reduce abortion rates. The criminalization of abortion causes women to turn to illicit abortions which often result in increased maternal morbidity and mortality. Presently, the revision of the Sri Lankan Abortion Law is approved by the cabinet, however the parliament approval has been withheld due to religious barriers.

\section{Female genital mutilation}

The WHO recognizes female genital mutilation as an extreme form of discrimination and violation of the human rights of young girls, which reflects inequality between the sexes. It is considered as torture under the Children's Charter. It causes decreased pleasure and pain during intercourse with reduced frequency or absence of orgasm.

This practice is carried out in Sri Lanka among young girls of a specific ethnic group to a great extent in a silent manner. Complaints have been made to the Women and Gender Subcommittee of the Parliament to ban the procedure by a women activist's group. As a result, the Ministry of Health has issued a circular prohibiting female genital mutilation by medical professionals. Further, legal changes need to be done to protect young girls. 


\section{Young offenders and orphaned children}

The Children and Young Persons Ordinance protects the rights of young people who are victims of an offence. However, young offenders who are in the prison correctional institute should stay for three full years irrespective of their offence. There are no structured heath programmes including SRH or psychological support available for young people who are in the prison correctional institutes other than HIV prevention services. The fate is the same with orphaned children. It is emphasized that the authorities need to pay urgent attention to this fact.

\section{Inequalities and SRH rights}

Inequities can be due to economic, social and gender imbalance. Health inequalities lead to violation of SRH rights. Health inequalities are defined as differences in the health status or in the distribution of health determinants between different population groups. It is often used as a proxy for social cohesion that affects young people's lives. The DHS 2016 revealed that many poor health indicators are prevalent in the rural sector, lower wealth strata and in younger age groups.

Social determinants of health have influences on inequalities at many levels and an impact on the health of young persons, including on SRH outcomes. Macro determinants are political contexts, governance, policies, culture and societal values. Intermediate determinants include the conditions in which people are born, grow, live, work and age, including the health system. Behavioural and biological factors are considered as individual determinants. Although community and structural determinants remain consistently influential during the life course, influence by the family of origin gradually decreases as young people achieve gradual independence with time. Factors outside of the family become greater influencing factors among young people's lives. Peers, media and education become the highest influential factors during young life.

Gender inequality is explained as unequal power relationships between men and women due to gender roles and unequal laws. Sri Lankan young people face gender inequities in many levels that result in economic violence and economic abuse, which are more prevalent among younger groups. In a review conducted by Bill and Melinda Gates Foundation in 2015, it was revealed that 128 countries including Sri Lanka had at least one legal obstacle for women's participation in certain economic opportunities. The review found that, in 18 countries, men could legally prevent their wives from working outside home.

Closing the gender gap in workforce participation would reduce poverty and increase the global GDP by nearly $12 \%$ by 2030 . Forty percent of women contributes to the labour force in both global and Sri Lankan contexts. Gender inequalities can prevent young people from entering economic opportunities and affect young people's SRH outcomes. It is known that the female political participation is less than $6 \%$ in parliament in Sri Lanka. The gender wage gap as a ratio of female to male average incomes should be closer to one, if inequalities are minimal, whereas in Sri Lanka, the figure was 0.3 in 2016. Further, when considering the legal systems of different countries that have gender differences in family, labour and criminal law, Sri Lanka has $20 \%$ gap to come to the zero level according to 2015 data. Gender inequality norms can influence a young girl entering the labour force and the types of jobs she may pursue. Even the advertisements published in printed media by certain institutes and for certain types of jobs and trainings, only target males.

\section{Gender-based violence}

Gender based violence against young girls is concealed as private family matters in Sri Lanka. The DHS 2016 revealed that $17 \%$ of ever-married women have suffered from intimate partner violence, with the lowest wealth strata and lower age category having a higher prevalence of intimate partner violence. Several studies show that young Sri Lankan women are subjected to sexual harassments than those in older age groups.

\section{Quantifying inequality and impacts identified}

Gender Inequality Index is the inequality between women and men in three dimensions of reproductive health, empowerment areas such as political participation and education, and labour market participation. It directly affects the SRH outcomes of young girls. It is 0.673 for Sri Lanka, which indicates that inequality is quite high. The Human Development Index (HDI) is an average measure of basic human development 
achievements in a country. It was increased from 0.746 in year 2010 to 0.766 in year 2015 in Sri Lanka. In all developed countries, the values are above 0.8 . The Inequality Adjusted Human Development Index (IHDI) is calculated adjusting the 'loss' in human development based on the inequality in all social determinants. This has changed from 0.64 in 2013 to 0.678 in 2015, which is a dramatic decline compared to the HDI. This means that inequalities in development are getting wider in Sri Lanka. In the developed world, there is not much of a difference between HDI \& IHDI. Inequality is significantly and negatively associated with health of a person, education and per capita income levels for HDI, which means that when inequality increases in health, education and income, it decreases the HDI. Further, when inequality increases in female primary education, the GDP per capita and gender inequality, it increases the maternal mortality.

A wage equality value closer to one indicates a similar wage for similar work between men and women. The World Economic Forum (2006) has shown that the reduction of the gender wage gap leads to a reduction in the adolescent birth rate. This could be considered as one reason for the static Sri Lankan adolescent birth rate during the last four decades. However, there is no recent consistent gender wage gap analysis found for Sri Lanka.

\section{SRH service coverage and financial risk protection}

The SRH services range from sexuality education for adolescents to treatment of cancers of the reproductive system. When the SRH service coverage and the financial risk protection in the Asia Pacific Region is considered, Sri Lanka gives less than $60 \%$ due to lack of sexual education for adolescents.

\section{Best investment to improve SRH in young people}

One of the best and most cost-effective investments in young people is age-appropriate comprehensive sexual education. There are also some wellknown SRH advocates in the country. However, when such education is given at schools, sometimes issues may arise, such as doubts that it could lead to an increase of early sex life. However, evidence shows otherwise. Abstinence only sex education has been proven as ineffective.
Comprehensive sex education (CSE) includes ageappropriate, medically accurate information on a broad set of topics related to sexuality. It enables SRH promotion among young people, and in the long- as well as short-term, enable young people to set boundaries and understand values and responsibilities of a healthy sexual life. Evidence from different countries has shown that CSE reduces risky behaviour. A review of 87 studies including meta-analysis has shown that CSE decreases STI/ HIV, violence, early marriages, sexual abuse, early sexual initiation, abortions and homophobia. Comprehensive sex education improves tolerance, mutual understanding, respect and understanding the diversity. When there is no sex education, dislike, prejudice/ homophobia, discrimination, stigma and hate/ violence can prevail.

\section{Present situation of CSE in Sri Lanka}

Many content areas on sexual health have been incorporated into the school curriculum to the Health and Physical Education subject, except sexual citizenship education. It is an optional subject that is taken up by only $40 \%$ of the students. Sexual health has been incorporated within the subject of 'Health and Wellbeing' for the students who follow the vocational training stream since 2017 with teacher training at present. However, many stakeholders including the Ministry of health, UNFPA and NGO sector are carrying out ad-hoc programmes to fulfil the current need without incorporating them into the existing curriculum. At present, the Women and Gender Sub-committee of the Parliament gives directives for the incorporation of sexual health content into the curriculum. The major challenge however is the lack of skills among teachers. The next revision of the curriculum is eagerly awaited.

\section{Hands Up for Smart Investment of Youth}

In conclusion, even though we cannot always build the future for our youth, we can build our youth for the future. We should invest in youth to shape their future to be healthy. Understand them, listen to them, care for them, facilitate them and allow them.

World Health Organization, United Nations Children's Fund, United Nations Population Fund, World Bank Group and the United Nations Population Division, 2015. 


\section{References}

American Psychological Association. Answers to your questions: for a better understanding of sexual orientation and homosexuality. Washington, DC: Office of Public and member Communication, 2002.

Barnett B \& Stein J. Women's voices, women's lives: the impact of family planning, a synthesis of findings from the Women's Studies Project. Research Triangle Park, NC, USA: Family Health International, 1998.

Beyond 2015. Population dynamics: realizing the future we want for all. UN System Task Team on the POST-2015. UN Development Agenda, Global Thematic Consultation, 2013.

Bhutta ZA, Makrides M, Prentice AM (eds). Health and nutrition in adolescents and young women: preparing for the next generation. Nestlé Nutrition Institute Workshop Series. Vol. 80: 61-69. Nestec Ltd., Vevey/S. Karger AG., Basel, 2015.

Carroll A \& Mendos LR. State sponsored homophobia 2017: a world survey of sexual orientation laws: criminalization, protection and recognition. Geneva: International Lesbian, Gay, Bisexual, Trans and Intersex Association, 2017.

Cochran S, Drescher J, Kismödi E, Giami A, GarcíaMoreno C, Atalla E, Reed GM. Proposed declassification of disease categories related to sexual orientation in the international statistical classification of diseases and related health problems (ICD-11). Bulletin of the World Health Organization 2014: 92(9): 672-679.

Castle S \& Diallo V. Desk review of evidence about violence within educational settings in West and Central Africa. Report for Plan West Africa. Save the Children Sweden, ActionAid and the UNICEF, 2008.

CIDA. Securing the future of children and youth: CIDA's children and youth strategy. Canadian International Development Agency, 2011.

Cebulla A \& Tomaszewski W. Risky behaviour and social activities. Report No. DCSF-RR173. Department for Children, Schools and Families. UK: National Centre for Social Research, 2009.

Chaaban J \& Cunningham W. Measuring the economic gain of investing in girls: the girl effect dividend. Policy Research Working Paper 5753. The World Bank Human Development Network. Children and Youth Unit \& Poverty Reduction and Economic Management Network. Gender Unit, 2011.
Chambers R \& Lake A. Youth Business International: Bridging the gap between unemployment and selfemployment for disadvantaged youth. Skills Working Paper No. 3. InFocus Programme on Skills, Knowledge and Employability. Geneva: International Labour Office, 2002.

Cling JP, Gubert F, Nordman C, Robilliard A-S (Eds). Youth and labour markets in Africa. A critical review of literature. Paris: DIAL, 2007.

Comyn P. Review of the structure \& coordination of skills development in Bangladesh. TVET Reform Project, 2009.

Cunningham W et al. Youth at risk in Latin America: understanding causes, realizing the potential. Washington DC: World Bank, 2008.

Currie C. Social determinants of health and wellbeing among young people. Health Behaviour in School-aged Children (HBSC) Study. International Report from the 2009/2010 Survey (Health Policy for Children and Adolescents, No. 6). Copenhagen: WHO Regional Office for Europe, 2012.

DFID. A new strategic vision for girls and women: stopping poverty before it starts. Department for International Development, 2011.

Dollar D \& Gatti R. Gender inequality, income and growth: are good times good for women? World Bank Policy Research Working Paper 2881. Washington DC: World Bank, 1999.

European Commission. A decent life for all: ending poverty and giving the world a sustainable future. Communication from the Commission to the European Parliament, the Council, the European Economic and Social Committee and the Committee of the Regions. Brussels: EC, 2013.

Darroch J, Woog V, Bankole A, Ashford LS. Adding it up: costs and benefits of meeting the contraceptive needs of adolescents. New York: Guttmacher Institute, 2016.

Democratic Socialist Republic of Sri Lanka. Vagrants Ordinance: No. 4 of 1841. Sri Lanka, 1842.

Democratic Socialist Republic of Sri Lanka. $365 \&$ 365A in Penal Code. Sri Lanka, 1995.

Department of Gender and Women's Health, Family and Community Health. Putting women's safety first: ethical and safety recommendations for research on domestic violence against women (WHO/FCH/GWH/ 01.1). Geneva: World Health Organization, 2001. 
Every Woman Every Child. The Global Strategy for Women's, Children's and Adolescents' Health (20162030). Private Sector Pre-conference Consultation, New Delhi, February 2015.

Filippi V, Chou D, Ronsmans C, Graham W, Say L. Levels and causes of maternal mortality and morbidity. In: RE Black, R Laxminarayan, M Temmerman, et al (Eds.). Reproductive, maternal, newborn, and child health: disease control priorities. Third Edition (Volume 2). Washington (DC): International Bank for Reconstruction and Development - The World Bank, 2016.

Ganchimeg T, Ota E, Morisaki N, Laopaiboon M, Lumbiganon P, Zhang J, Mori R (2014). Pregnancy and childbirth outcomes among adolescent mothers: a World Health Organization multicountry study. BJOG 2014; 121(Suppl 1): 40-48.

Government of Sri Lanka. Brothels Ordinance - Section 2 (1889). Colombo, Sri Lanka.

Guruge S, Jayasuriya-Illesinghe V, Gunawardena N, Perera J. Intimate partner violence in Sri Lanka: a scoping review. Ceylon Medical Journal 2015; 60: 133-138.

Hardee K, Kumar J, Newman K, Bakamjian L, Harris S, Rodríguez M, Brown W. Voluntary, human rightsbased family planning: a conceptual framework. Studies in Family Planning 2014; 45(1): 1-18.

Hogan RM. Human sexuality: a nursing prospective. USA: Appleton-Century-Crofts, 1980.

De Silva I. Demographic dividend of Sri Lanka and future development prospects. Sri Lanka Journal of Social Sciences 2014; 37(1-2): 7-17.

UNAIDS/JC2910E. UNAIDS Data 2017. Terminology Guidelines. Geneva: Joint United Nations Programme on HIV/AIDS, 2015.

Kumara S, Guruge GGN, Perera KMN, Senarathna L. Determinants/risk factors of teenage pregnancy identified by school going teenagers. Third Biennial Meeting of SASSM. 19-21 November, Colombo, Sri Lanka, 2017.

Ministry of Health. General Circular: Issuing of Gender Recognition Certificate for Transgender Community, 2016 01-34/2016. Colombo, Sri Lanka.

Neal S, Matthews Z, Frost M, Fogstad H, Camacho AV, Laski L. Childbearing in adolescents aged 12-15 years in low resource countries: a neglected issue.
New estimates from demographic and household surveys in 42 countries. Acta Obstetricia et Gynecologica Scandinavica 2012; 91(9): 1114-1118.

NSACP. National HIV/AIDS Policy Sri Lanka. Colombo: National STD/ AIDS Control Programme, 2012.

NSACP. Integrated Biological and Behavioural Surveillance (IBBS) Survey Among Key Populations at Higher Risk of HIV in Sri Lanka. Colombo: National STD/AIDS Control Programme, 2015.

NSACP. Annual Report 2016. Colombo: National STD/AIDS Control Programme, Ministry of Health, 2017.

Stenberg K, Axelson H, Sheehan P, Anderson I, Gülmezoglu M, Temmerman M, Mason E, Friedman HS, et al. Advancing social and economic development by investing in women's and children's health: a new global investment framework. Lancet 383(9925):13331354.

UNICEF. Ending child marriage: progress and prospects. New York: United Nations Children's Fund, 2013.

US Department of Justice. Extent, nature and consequences of intimate partner violence: findings from the National Violence Against Women Survey. Washington, 2000.

UN. Declaration on the elimination of violence against women. New York: United Nations, 1993.

UNICEF. Fact Sheet on Young People and Family Planning: Teenage Pregnancy. Malaysia: United Nations International Children's Emergency Fund, 2008.

UNFPA. Adolescent pregnancy: a review of the evidence. New York: United Nations Population Fund, 2013.

UNFPA. Girlhood, not motherhood: preventing adolescent pregnancy. New York: United Nations Population Fund, 2015.

UNDESA. World Population Prospects: the 2015 Revision. New York: United Nations Department of Economic and Social Affairs, Population Division, 2015.

UNDESA. World Population Prospects: the 2017 Revision. New York: United Nations Department of Economic \& Social Affairs, Population Division, 2017. 
UNDESA. SDG Indicators: Global Database. New York: United Nations Department of Economic \& Social Affairs, Statistics Division, 2017.

UN. Program of Action at the International Conference on Population and Development. 5-13 September 1994. New York: United Nations, 1995.

Vidanapathirana J \& Dissanayake N. Social behaviour change communication for HIV prevention: a guide for public health staff. Colombo: National STD/AIDS Control Programme \& United Nations Population Fund, 2015.

Vidanapathirana J, Premadasa P, Disanayake N, Wijegoonewardene N. No one left behindunderstanding key populations: achieving triple zeros by 2030. Colombo: National STD/AIDS Control Programme \& United Nations Population Fund, 2016.

Vidanapathirana J, Premadasa P, Disanayake N, Wijegoonewardene N, Mallikarachchi D. Let us know about HIV/AIDS: achieving triple zeros: handbook on HIV \& AIDS for primary healthcare workers. Colombo: National STD/AIDS Control Programme \& United Nations Population Fund, 2016.

Vidanapathirana J, Senanayake B, Wijegoonewardene $\mathrm{N}$, Fernando M. Zero stigma and discrimination by 2020: stigma assessment of people living with HIV in Sri Lanka. Colombo: National STD/AIDS Control Programme \& United Nations Population Fund, 2017.

Vidanapathirana, J, Wijegoonewardene N, Senanayake B, Fernando M. No secrets, know the facts, disarm myths, know about sexuality, 100 facts. Colombo: National STD/AIDS Control Programme, 2017.

Vidanapathirana HMJP, Senanayake B, Fernando TSM, Wijegoonewardene MNYF, De Silva LSD (2018). Attitudes among Sri Lankan professionals towards men who have sex with men. Colombo: National STD/ AIDS Control Programme, 2018.

Vidanapathirana HMJP, Senanayake B, Fernando TSM, Wijegoonewardene MNYF, De Silva LSD. Attitudes among Sri Lankan professionals towards transgender personnel. Colombo: National STD/AIDS Control Programme, 2018.
Igras SM, Macieira M, Murphy E, Lundgren R. Investing in very young adolescents' sexual and reproductive health. An International Journal for Research, Policy and Practice 2014; 9(5): 555-569.

Volpe U. The development of the ICD-11 chapter on mental disorders. South African Journal of Psychiatry 2017; 23(0): a1105.

World Bank. Economic Impacts of Child Marriage: Global Synthesis Report. Washington DC: World Bank, 2017.

WHO. Manual of The International Statistical Classification of Diseases, Injuries, and Causes of DEATH (10th edition). Geneva: World Health Organization, 1992.

WHO. Report of the Consultation on Child Abuse Prevention. Geneva: World Health Organization, 1999.

WHO. WHO Guidelines on Preventing Early Pregnancy and Poor Reproductive Outcomes Among Adolescents in Developing Countries. Geneva: World Health Organization, 2011.

WHO. Global and Regional Estimates on Violence Against Women: Prevalence and Health Effects of Intimate Partner Violence and Non-Partner Sexual Violence. Geneva: World Health Organization, 2013.

WHO. Sexual and reproductive health. Available from: http://www.who.int/reproductivehealth/ topics/sexual_health/sh_definitions/en/.

WHO. Fact Sheet on Female Genital Utilization. Geneva: World Health Organization, 2008.

WHO, UNICEF, UNFPA, WB Group, UNPD. Trends in maternal mortality: 1990 to 2015. Geneva: World Health Organization, United Nations Children's Fund, United Nations Population Fund, World Bank Group and the United Nations Population Division, 2015.

WHO. Global Health Estimates 2015: Deaths by Cause, Age, Sex by Country and Region 2000-2015. Geneva: World Health Organization, 2016. 